\title{
Average Current Mode Control of High Voltage DC Power Supply for Pulsed Load Application
}

\author{
N.Vishwanathan, Dr. V.Ramanarayanan \\ Power Electronics Group, Dept. of Electrical Engineering, \\ Indian Institute of Science, \\ Bangalore -- 560 012, India. \\ e-mail: nvn@ee.iisc.ernet.in, e-mail: vram@ee.iisc.ernet.in
}

\begin{abstract}
High voltage power supplies with pulse load (125 $\mathrm{KHZ}$ and $10 \%$ duty cycle) is investigated which are of interest for applications like radar power supplies with output voltage of $22 \mathrm{KV}$. The performance specifications with this type of power supplies are very stringent demanding tight regulation $(<0.01 \%)$ and high efficiency ( $>85 \%)$. This paper proposes a methodology to tackle the problems associated with this type of application. Phase-modulated series resonant converter with ZVS is used as the power converter. Average value of the rectified tank current is controlled to regulate the output voltage. Synchronization of converter switching with load pulses enables the converter to switch at half the load switching frequency. Low switching frequency helps in ensuring safety of $\mathrm{HV}$ transformer insulation and reduction of losses due to skin \& proximity effect. Average current mode control gives excellent dynamic response with simple closed loop design.
\end{abstract}

Keywords - high voltage power supply, phase-modulated series resonant converter, average current mode control, pulse load.

\section{INTRODUCTION}

High voltage power supplies find wide range applications as power sources for industrial equipment, medical equipment, air borne applications etc. In many high-power, high-voltage applications such as traveling wave tube (TWT) RF generation, laser based systems for industrial applications (like cutting, marking or surface treatment), X-ray equipment, radar power supplies, there is a requirement for high quality power. In these applications, the power converter may be subjected to either static /slow varying loads or loads with pulsed nature. Radar power supplies are subjected to pulsed loads.

Several converters have been proposed in the past to produce and regulate high voltage D.C. Initially they were meant for satellite power supplies [1], [2]. Later these converters were used for other applications. In all high voltage power supplies, the HV transformer is a crucial element. It is due to the large no. of secondary turns and insulation requirements. These two aspects exacerbate the transformer non-idealities, which are winding capacitance and leakage inductance. In all the high-voltage DC-DC power converters, attempt has been made to absorb these non-idealities as useful elements in the power converter topology. It has resulted in series resonant converter (SRC), parallel resonant converter (PRC), series-parallel resonant converter (SPRC) with their own advantages and disadvantages. From the control aspect of these converters, two methods are present i.e., variable frequency control and constant frequency phase-modulated control [6]. Phase modulation is generally preferred due to constant switching operation, which yields optimum design of reactive elements. Phase modulated resonant converter is shown in fig. 1. The equivalent ckt. of the HV transformer and various resonant tank circuits are shown in fig. 2 and fig. 3 respectively.

In $\mathrm{SRC}$, the series capacitor eliminates the possible saturation of the HV transformer. Capacitive filter at the output is possible. The leakage inductance of the HV transformer is absorbed into the resonant tank ckt. This topology gives high efficiency over a wide range of load variations. The only drawback is that it doesn't absorb the parasitic winding capacitance into the resonant tank ckt. Though it is a limiting factor, the SRC has been used in the high-voltage, high-power converters due to several other advantages [4].

The PRC absorbs the winding capacitance into the resonant tank ckt. But the PRC requires an $\mathrm{LC}$ filter at the output. In high voltage applications, the size of the output filter inductance becomes comparable to the size of the transformer, which is prohibitive. It has been shown in [3] that it is possible to remove this component without degrading the performance of the converter. Even then the PRC has the limitations like, the saturation problem in the HV transformer can occur in full bridge topology. Another drawback of PRC is that the current in the resonant components is relatively independent of the load, and the efficiency of the converter is relatively low for light loads.

The series-parallel resonant converter (SPRC) combines the advantages of the series and parallel converters. The output is controllable for no-load or light-loads, and the light load efficiency is high. In [5], SPRC has been proposed for pulsed load applications. It absorbs all the parasites of the HV transformer. The converter is operated with phase-shifted PWM control at slightly variable frequency. But the hybrid converters are complex to analyze and difficult to control.

This paper presents a converter topology for highvoltage DC power supplies subjected to pulse loads. Pulse loading exists in applications like radar power supplies with high pulse repetition frequency (PRF). The performance specifications with this type of power supplies are very stringent demanding tight output voltage regulation and high efficiency. Proposed solutions are applied to a prototype with 


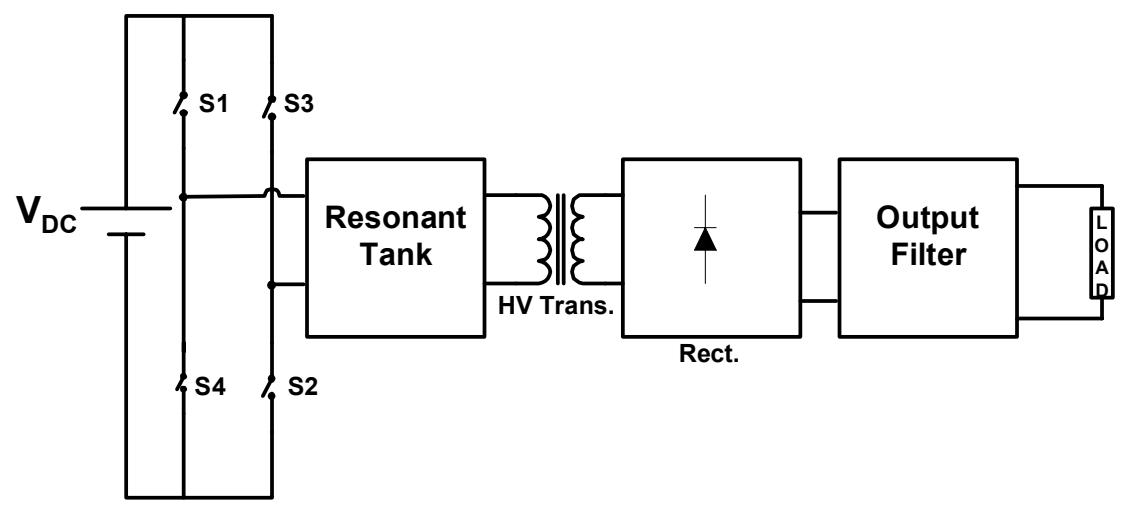

Figure 1. Phase-modulated resonant converter

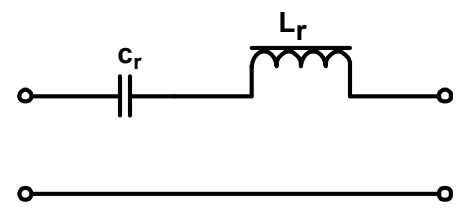

(a) series

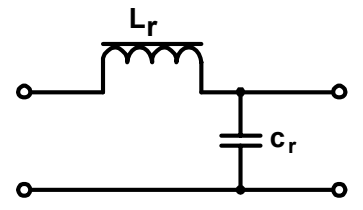

(b) parallel

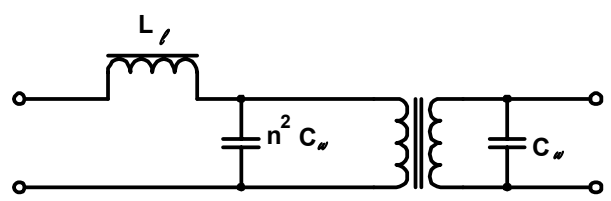

1:n

Figure 2. Equivalent circuit of the HV transformer

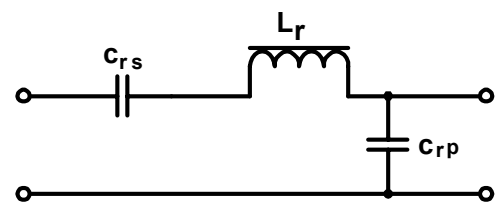

(c) series-parallel

Figure 3. Resonant tank circuits

Table-I

\begin{tabular}{|l|l|}
\hline Supply Voltage: $270 \mathrm{VDC} \pm 10 \%$ & Regulation: $<0.01 \%$ \\
\hline Output Voltage: $1 \mathrm{KV}$ & Droop: $0.5 \mathrm{~V} / \mu$ sec. \\
\hline Peak Power: $6 \mathrm{KW}$ & Load Switching Freq.: $125 \mathrm{KHz}$ \\
\hline Average Power: $600 \mathrm{~W}$ & Efficiency: $>85 \%$ \\
\hline
\end{tabular}

the specifications in table-I and fig.4. Actual application requires output voltage and average power level of $22 \mathrm{KV}$ and $1.25 \mathrm{KW}$ respectively.

As the load switches at high frequency, if the converter is not regulated properly, the output voltage may collapse totally over a period of time. The converter should switch atleast at twice the load switching frequency for good regulation and stable operation. Tackling high frequency, high voltage, high power and tight regulation in one power converter is a challenging issue. The combination of "high power \& high frequency inverter" and "high frequency \& high voltage transformer" are critical blocks resulting in number of compromises in terms of output regulation, response time etc.

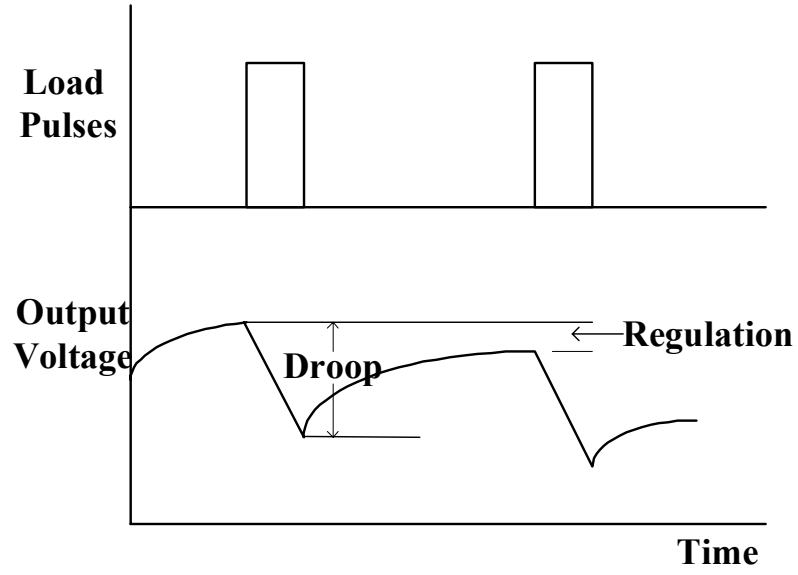

Figure 4

The problems encountered in general with high voltage and high frequency transformer are: 1) Insulation failure, 2) Skin \& proximity effect resulting in increased copper losses and temperature rise, 3) Increased iron losses, 4) Parasites of HV transformer i.e., leakage reactance results in poor 
regulation and secondary winding capacitance results in current spikes and delay.

Hence, the above-mentioned problems lead to the development of a methodology with single stage power conversion adopting a medium switching frequency and still satisfying the performance specifications. The average current mode control (ACMC) seems to be a good control philosophy for this application. It is applied to a phase-modulated series resonant converter with zero voltage switching (ZVS). ACMC controls the average value of the rectified tank current and provides exactly the required amount of energy to the load even during the transients. Phase-modulated series resonant converter with ACMC helps in overcoming the problems of $\mathrm{HV} \& \mathrm{HF}$ transformer, provides fast transient response and good regulation without compromising the efficiency constraint. ACMC has high noise immunity and is free from Sub-harmonic oscillation.

\section{PHASE-MODULATED SERIES RESONANT CONVERTER}

Phase-modulated series resonant converter (PM-SRC) is a very practical approach for the high-voltage DC power supplies. The converter switches at a frequency slightly higher than the resonant frequency of the tank circuit, facilitating the ZVS of the devices with the aid of the capacitors connected across them. PM-SRC operates in three modes, namely, mode1 , mode-2, and mode- 3 . The relevant waveforms of the tank current, $\mathrm{i}(\mathrm{t})$, inverter output voltage, $\mathrm{V}_{\mathrm{AB}}$, resonant capacitor voltage, $\mathrm{v}_{\mathrm{c}}(\mathrm{t})$, and output voltage, $\mathrm{V}_{\mathrm{O}}$, under the three modes are shown in fig.5. The various sub-periods are shown as A, B, $\mathrm{C}, \mathrm{D}$, and $\mathrm{E}$. The general equations describing the LC tank circuit with excitation $\left(\mathrm{V}_{\text {in }}-\mathrm{V}_{\text {out }}\right)$ are given by

$$
\begin{aligned}
\mathrm{i}(\mathrm{t})= & \mathrm{I}(0) \cos \omega_{\mathrm{r}} \mathrm{t}+\frac{\left[\left(\mathrm{V}_{\text {in }}-\mathrm{V}_{\text {out }}\right)-\mathrm{V}_{\mathrm{c}}(0)\right]}{\mathrm{Z}_{\mathrm{c}}} \sin \omega_{\mathrm{r}} \mathrm{t} \\
\mathrm{v}_{\mathrm{c}}(\mathrm{t})= & -\left[\left(\mathrm{V}_{\text {in }}-\mathrm{V}_{\text {out }}\right)-\mathrm{V}_{\mathrm{c}}(0)\right] \cos \omega_{\mathrm{r}} \mathrm{t}+\mathrm{Z}_{\mathrm{c}} \mathrm{I}(0) \sin \omega_{\mathrm{r}} \mathrm{t} \\
& +\left(\mathrm{V}_{\text {in }}-\mathrm{V}_{\text {out }}\right)
\end{aligned}
$$

$\mathrm{I}(0)$ and $\mathrm{V}_{\mathrm{c}}(0)$ are initial values of $\mathrm{i}(\mathrm{t})$ and $\mathrm{V}_{\mathrm{c}}(\mathrm{t})$ respectively. $\mathrm{Z}_{\mathrm{c}}$ is the characteristic impedance of the LC ckt., and $\omega_{\mathrm{r}}$ is the resonant frequency. Current and voltage equations for each of the sub-period in different intervals are obtained by substituting the appropriate values of input \& output voltage and initial conditions in the above equations.

\section{AVERAGE CURRENT MODE CONTROL OF PM-SRC}

Block diagram of the proposed method is shown in fig.6. Phase-modulated series resonant converter is used as the power converter. Synchronization of converter switching with load pulses enables the converter to switch at half the load switching frequency. The converter is switched at $62.5 \mathrm{KHz}$ (half the load frequency), since rectified tank current will have same frequency as the load frequency. To have proper regulation of the output voltage, it is required to supply sufficient charge to the output filter capacitors to replenish the charge taken from them during the load. Hence. By properly controlling the tank current, this charge can be supplied to the output capacitors before the next load pulse. The converter is pulse loaded with a fixed load magnitude at constant frequency $(125 \mathrm{KHz})$ and fixed duty cycle $(10 \%)$. Though it is a pulse load, the average value of the load is constant. Hence, it can be considered as if the converter is being loaded with a constant load of value equal to average value of the pulse load. Out of the rectified tank current, load takes the average current and ripple current is taken by the filter capacitor. If average value of the rectified tank current is controlled to be constant with the proposed methodology, the output voltage can be regulated to be constant. Equivalent ckt. of fig. 6 is shown in fig.7. A reset integrator with $\mathrm{RC}$ time constant equal to the

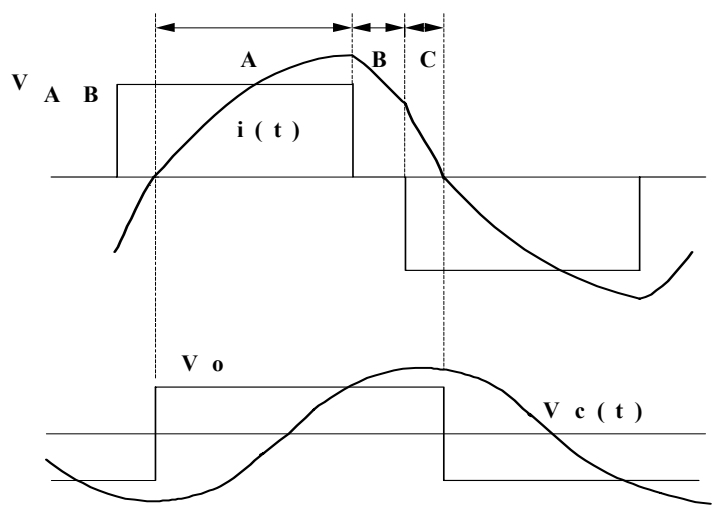

(a) Mode -1 operation

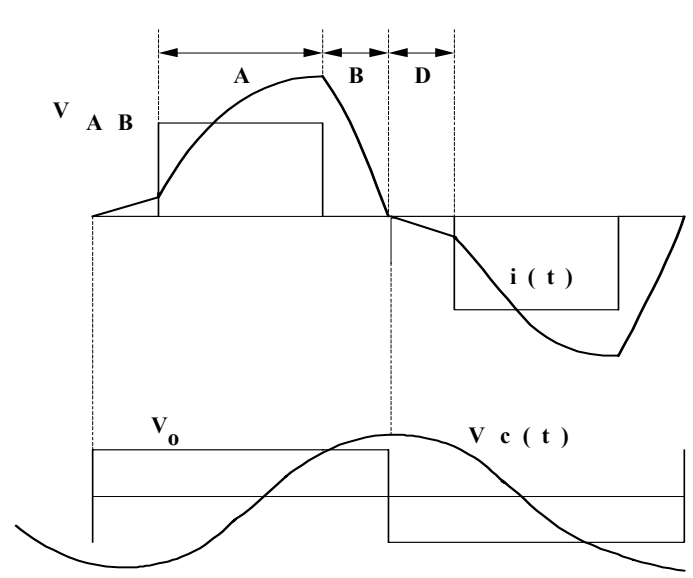

(b) Mode -2 operation

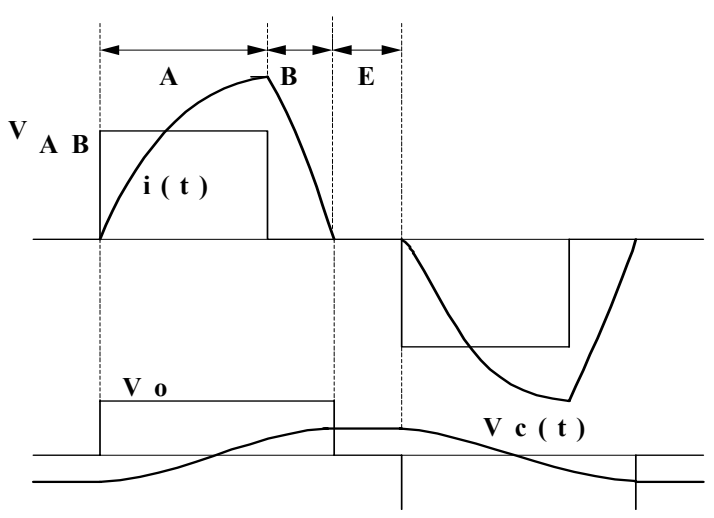

(c) Mode -3 operation

Figure 5. Waveforms of PM-SRC 


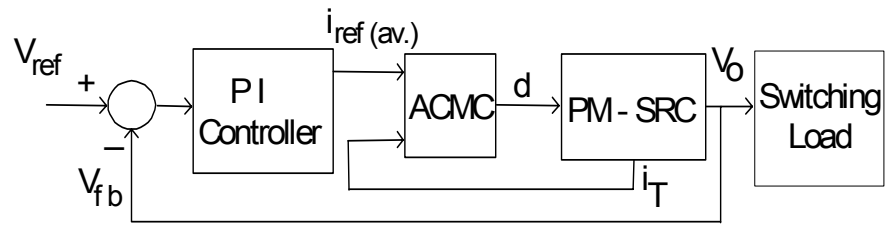

Figure 6. Block diagram of the ACMC

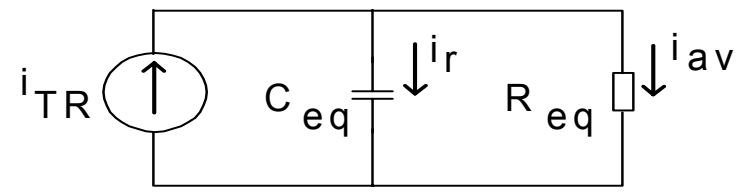

Figure 7. Equivalent ckt. of ACMC

time period of load pulses (Ts) does cycle-by-cycle averaging. In the fig.7, $\mathrm{V}_{\text {ref }}$ : reference signal, $\mathrm{V}_{\mathrm{fb}}$ : feedback signal, $\mathrm{i}_{\text {ref(av) }}$ : reference for average value of rectified tank current, $\mathrm{i}_{\mathrm{T}}$ : resonant tank current, d: duty cycle, $\mathrm{V}_{\mathrm{O}}$ : output voltage, ACMC: consists of rectifier for tank current, averaging ckt., and comparator, $\mathrm{i}_{\mathrm{TR}}$ : rectified tank current, $\mathrm{C}_{\mathrm{eq}}$ : equivalent output capacitance, $\mathrm{R}_{\mathrm{eq}}$ : average load, $\mathrm{i}_{\mathrm{r}}$ : ripple content of $i_{T R}$, and $i_{a v}$ : average value of $i_{T R}$.

Averaging process is shown in fig.8. In this, load voltage, output voltage, rectified tank current and average of the rectified tank current are shown. Averaging process is initiated from the instant freewheeling of the tank current starts. This is done to account for the initial value of the tank current also for averaging. Averaging continues till the averaged value reaches the reference set by the outer feedback loop. With this control, the tank circuit acts as a current source for charging the output capacitors. Thus the system has the first order behavior. Expressions for the average current and control to output transfer function are as follows.

$$
\mathrm{i}_{\mathrm{av} .}=\frac{1}{\mathrm{~T}_{\mathrm{S}}} \int_{0}^{\mathrm{T}_{\mathrm{S}}} \mathrm{i}_{\mathrm{TR}} \mathrm{dt}
$$

control to output transfer function $=\frac{\hat{\mathrm{v}}_{\mathrm{O}}}{\hat{\mathrm{i}}_{\mathrm{av}(\mathrm{ref})}}=\left(\frac{\mathrm{K}}{1+\mathrm{s} \tau}\right)$

where

$\mathrm{T}_{\mathrm{S}}=$ Time of averaging, $\mathrm{K}=$ control to output gain,

$\tau=$ Time constant

As the system has first order response, simple PI controller is used for the closed loop operation.

\section{DESIGN CONSIDERATIONS}

\section{A. Design of series resonant circuit}

The design process mainly involves the selection of resonant tank elements $(\mathrm{Lr} \& \mathrm{Cr}$ ) and transformer turns ratio (n). For this, all the parameters in the PM-SRC are normalized with respect to the base values. Table-II gives the list of the

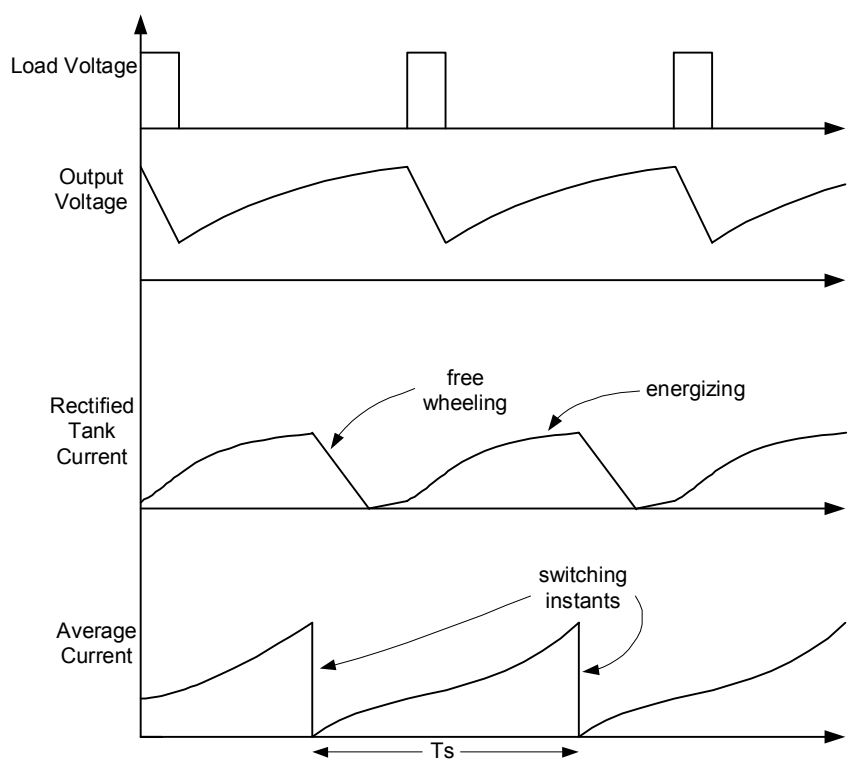

Figure 8

Table - II Base Variables

\begin{tabular}{|l|l|}
\hline \multicolumn{1}{|c|}{ Variables } & \multicolumn{1}{c|}{ Base Values } \\
\hline Voltage & Input DC Voltage $\mathrm{V}_{\mathrm{DC}}$ \\
\hline Resistance & Tank Char. Impedance, $\mathrm{Z}_{\mathrm{c}}$ \\
\hline Current & $\mathrm{I}_{\mathrm{B}}=\mathrm{V}_{\mathrm{DC}} / \mathrm{Z}_{\mathrm{c}}$ \\
\hline Frequency & Resonant frequency, $\omega_{\mathrm{r}}$ \\
\hline Capacitance & $\mathrm{C}_{\mathrm{r}}$ \\
\hline Inductance & $\mathrm{L}_{\mathrm{r}}$ \\
\hline
\end{tabular}

variables and corresponding base values. Thus the per unit values are $\mathrm{V}_{\mathrm{DC}}=1.0$ p.u., $\omega_{\mathrm{r}}=1.0$ p.u., $\mathrm{L}_{\mathrm{r}}=1.0$ p.u., $\mathrm{C}_{\mathrm{r}}=1.0$ p.u.

$$
\text { gain of the converter }(M)=\frac{V_{O}}{n \cdot V_{D C}}
$$

where $\mathrm{V}_{\mathrm{O}}=$ output voltage.

The performance of the PM-SRC is dependent on various parameters like tank inductance $\left(\mathrm{L}_{\mathrm{r}}\right)$, tank capacitance $\left(\mathrm{C}_{\mathrm{r}}\right)$, resonant frequency $\left(\omega_{\mathrm{r}}\right)$, switching frequency $\left(\omega_{\mathrm{S}}\right)$, load resistance $\left(\mathrm{R}_{\mathrm{L}}\right)$, duty cycle $(\mathrm{d})$, and transformer turns ratio (n).

To take into account the effect of these parameters, these are grouped together as follows:

$$
\begin{gathered}
\gamma=\frac{\omega_{\mathrm{S}}}{\omega_{\mathrm{r}}} \\
\zeta=\frac{\mathrm{Zc}}{\mathrm{R}_{\mathrm{L}^{\prime}}}
\end{gathered}
$$


where $\mathrm{Z}_{\mathrm{c}}=\sqrt{\mathrm{L}_{\mathrm{r}} / \mathrm{C}_{\mathrm{r}}}$ and $\mathrm{R}_{\mathrm{L}}{ }^{\prime}=\frac{\mathrm{R}_{\mathrm{L}}}{\mathrm{n}^{2}}$

Now these two variables i.e., $\gamma$ and $\zeta$ are used to study the performance of the PM-SRC. Since the PM-SRC has to be operated only above resonant frequency, its operation for $\gamma>1$ is studied. These two variables are varied to find the voltage stress on the tank capacitor, current stress on the tank circuit and voltage gain of the converter. Their effects are summarized in the following tables. Effects of $\gamma$ and $\zeta$ on the performance of PM-SRC are shown in tables-III \& IV respectively.

Table - III

\begin{tabular}{|c|c|c|c|}
\hline$\gamma$ & $\mathrm{M}$ & $\begin{array}{c}\text { Voltage } \\
\text { stress }\end{array}$ & $\begin{array}{c}\text { Current } \\
\text { stress }\end{array}$ \\
\hline 1.05 & 1.958 & 1.948 & 1.969 \\
\hline 1.1 & 1.859 & 1.769 & 1.831 \\
\hline 1.4 & 1.238 & 0.930 & 1.31 \\
\hline 1.8 & 0.8178 & 0.478 & 0.99 \\
\hline 2 & 0.709 & 0.378 & 0.88 \\
\hline
\end{tabular}

Table - IV

\begin{tabular}{|c|c|c|c|}
\hline$\zeta$ & $\mathrm{M}$ & $\begin{array}{c}\text { Voltage } \\
\text { stress }\end{array}$ & $\begin{array}{c}\text { Current } \\
\text { stress }\end{array}$ \\
\hline 3 & 1.117 & 10.05 & 10.48 \\
\hline 1 & 1.772 & 5.305 & 5.42 \\
\hline $1 / 2$ & 1.918 & 2.879 & 2.915 \\
\hline $1 / 4$ & 1.975 & 1.479 & 1.49 \\
\hline $1 / 6$ & 1.987 & 0.98 & 0.99 \\
\hline
\end{tabular}

For studying the effect of $\gamma$ on the performance of PM$\mathrm{SRC}, \zeta$ is kept at $1 / 3, \mathrm{n}$ is fixed at 1 (equivalent to no transformer in the ckt.), and duty cycle is fixed at 1 (square wave operation). It can be seen from table-III that the gain of the converter increases as the value of $\gamma$ tends to unity. Operation of the PM-SRC with $\gamma$ close to unity results in higher voltage and current stresses. If components with these values are available, then operation under this condition may be adopted as it results in higher gain of the converter and lower turns ratio of the transformer. Operation under $\gamma=1$ is not preferable as it results in loss of ZVS and SRC will lose inherent short circuit protection. Hence to have all the advantages of higher gain, ZVS, and inherent short circuit protection, operation with $\gamma=1.05$ is selected. Table-IV gives the effect of $\zeta$ on the operation of PM-SRC. During this study, the values of $\gamma, \mathrm{d}$, and $\mathrm{n}$ are fixed at $1.05,1$, and 1 respectively. It is observed that as the value of $\zeta$ is decreased below unity, the voltage gain is increased while the voltage and current stresses are decreased. Thus the operation of PM$\mathrm{SRC}$ for $\zeta<1$ is preferred.

Operation of PM-SRC at $\zeta=1 / 6$ is preferred as it results in a voltage gain close to 2 . It is the max. gain of SRC with voltage doubler at the output. The stresses on tank elements are less than 1 p.u. The design parameters are $\gamma=1.05, \zeta=$ $1 / 6$ and $\mathrm{M}=1.987$. PM-SRC can be designed using equations (5), (6), (7), selected design parameters, and power rating of the converter. It is designed under the condition of low source voltage where it can reach square wave mode of operation. The values of the components obtained are:

$$
\mathrm{L}_{\mathrm{r}}=173.21 \mu \mathrm{H}, \mathrm{C}_{\mathrm{r}}=41.3 \mathrm{nF}, \mathrm{n}=2.07
$$

\section{B. Design of output filter}
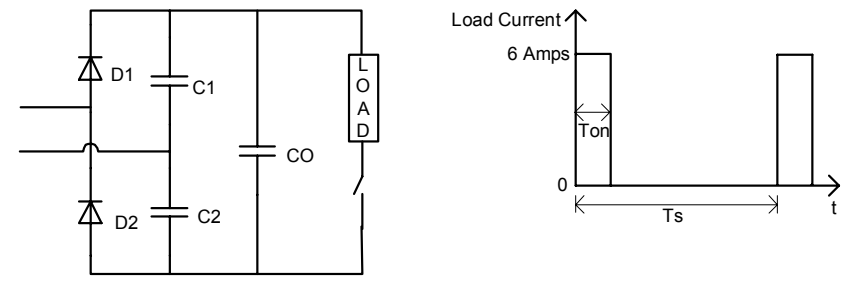

Figure 9

Output filter design is based on the voltage droop $\left(\frac{\mathrm{dv}_{\mathrm{O}}}{\mathrm{dt}}\right)$ and the peak load current $\left(\mathrm{I}_{\mathrm{p}}\right)$. Output section with a voltage doubler and capacitive filter along with load current waveform are shown in fig.9. Let,

$$
\mathrm{C} 1=\mathrm{C} 2=\mathrm{C} \text { and } \mathrm{Co}=10 \mathrm{C}
$$

The effective capacitance seen by the load be $\mathrm{C}_{\text {eff }}$.

$$
\mathrm{C}_{\text {eff }}=\left(\mathrm{Co}+\frac{\mathrm{C}}{2}\right)=1.05 \mathrm{C}_{\mathrm{o}}
$$

During the pulse load the charge supplied by $\mathrm{C}_{\mathrm{eff}}$ be $\mathrm{dQ}$.

$$
\mathrm{dQ}=\mathrm{C}_{\mathrm{eff}} \cdot \mathrm{dv}_{\mathrm{O}}
$$

also $\mathrm{dQ}=\mathrm{I}_{\mathrm{p}}$.Ton $=6 * 0.8 \times 10^{-6}=4.8 \mu \mathrm{C}$

$\mathrm{dv}_{\mathrm{O}}=(0.5 \mathrm{~V} / \mu \mathrm{sec}) \cdot(0.8 \mu \mathrm{sec})=0.4 \mathrm{~V}$ 
From equations (8), (9), and (10),

$$
\begin{gathered}
\mathrm{C}_{\text {eff }}=12 \mu \mathrm{F}, \mathrm{C}_{1}=\mathrm{C}_{2}=1.143 \mu \mathrm{F} \text {, and } \mathrm{C}_{\mathrm{O}}=11.43 \mu \mathrm{F} . \\
\text { V. } \quad \text { RESULTS }
\end{gathered}
$$

Following are waveforms of the proposed converter under closed loop operation. Fig.10 (a) \& (c) are the waveforms under nominal supply voltage of 270 V. Fig. 10 (b) \& (d) are waveforms for step response under supply voltage perturbation from $243 \mathrm{~V}$ to $297 \mathrm{~V}$.

In fig.10 (a) various currents like transformer secondary current, currents through $\mathrm{C}_{1} \& \mathrm{C}_{\mathrm{O}}$ and load current are shown. Sum of the currents through $\mathrm{C}_{1} \& \mathrm{C}_{\mathrm{O}}$ and load current are equal to the transformer secondary current. During the pulse load majority of the load current is supplied by $\mathrm{C}_{\mathrm{O}}$ and the remaining small portion by the series combination of $C_{1} \& C_{2}$. This is due to the fact that value of $C_{0}$ is 10 times larger than that of either $\mathrm{C}_{1}$ or $\mathrm{C}_{2}$. It can be observed that load takes the fixed average current and capacitors take the ripple current from the secondary of the transformer.

Fig.10 (b) gives the step response of tank current and inverter output voltage. Under this condition, the waveforms settle to the new steady state in less than $200 \mu$ - secs.

Fig.10 (c) shows waveforms of load voltage, output voltage, tank current, inverter output voltage, average current reference, and average of the rectified tank current under nominal supply voltage. It can be observed that droop in the output voltage is less than $0.5 \mathrm{~V} / \mu-\mathrm{sec}$. and regulation is less than $0.001 \%$. The small ripple in the average current reference is due to the ripple in the output voltage. This is because the reference is generated by sensing the output voltage itself.

Fig.10 (d) shows some more aspects due to step change in supply voltage from $243 \mathrm{~V}$ to $297 \mathrm{~V}$. The average current reference immediately reduces its value to reduce the average current to maintain constant power drawn from the source as per the control philosophy of this topology. In effect, the duty cycle of the inverter output voltage reduces. Due to this step change, the $\%$ overshoot in the output voltage is only $0.01 \%$. This is because of the fast response of the control loop.

\section{CONCLUSIONS}

The proposed average current mode control of HV power supply is studied under various line and pulse load conditions. The output voltage regulation is found to be $<0.001 \%$ and droop is less than $0.5 \mathrm{~V} /$ micro-sec. As the converter precisely controls the tank energy as per the load requirement, during the step change in supply voltage, output voltage overshoot is only $0.01 \%$. It is a very positive feature for $\mathrm{HV}$ power supplies. Even this little overshoot is due to the ripple in the average current reference generated, which in turn is due to the ripple in the output voltage. The switching frequency being half the load switching frequency (synchronized), the HV transformer insulation is very safe from failure and overall losses are very less giving overall efficiency $>85 \%$.
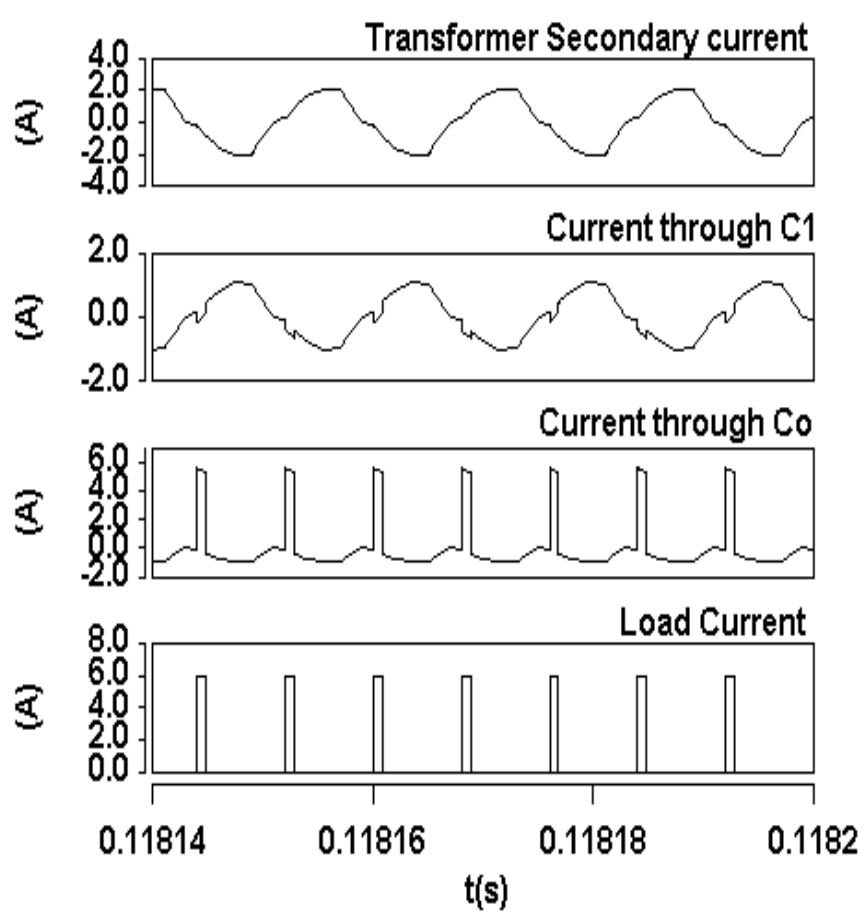

Figure 10 (a)
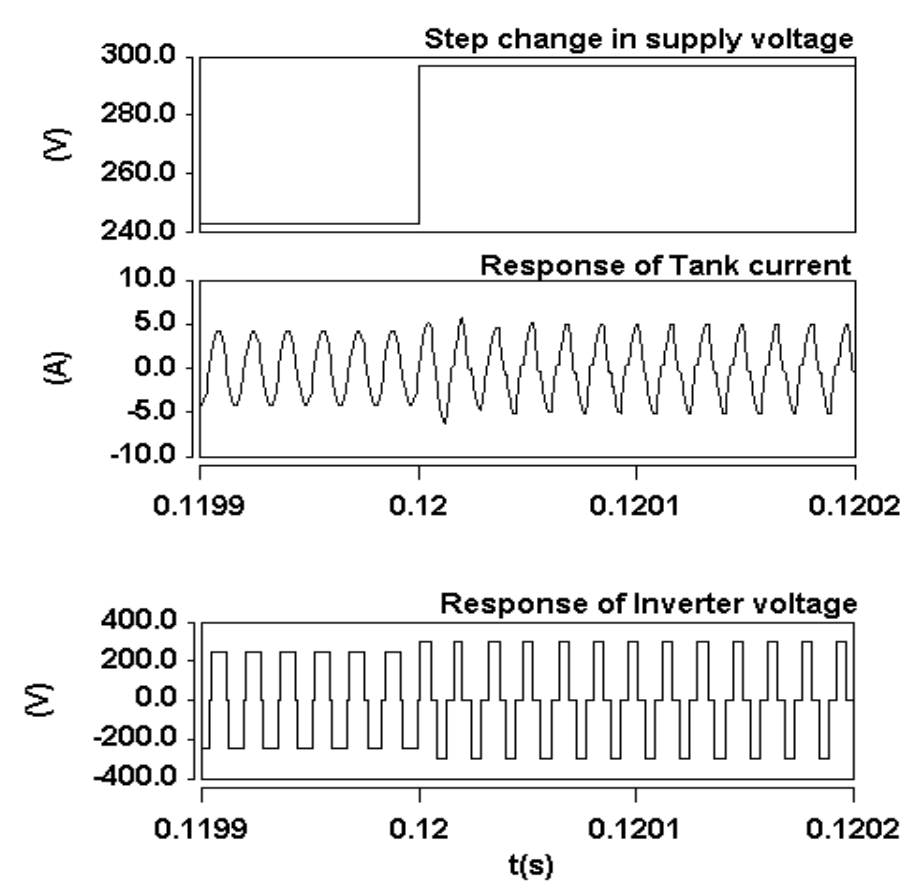

Figure $10(b)$ 

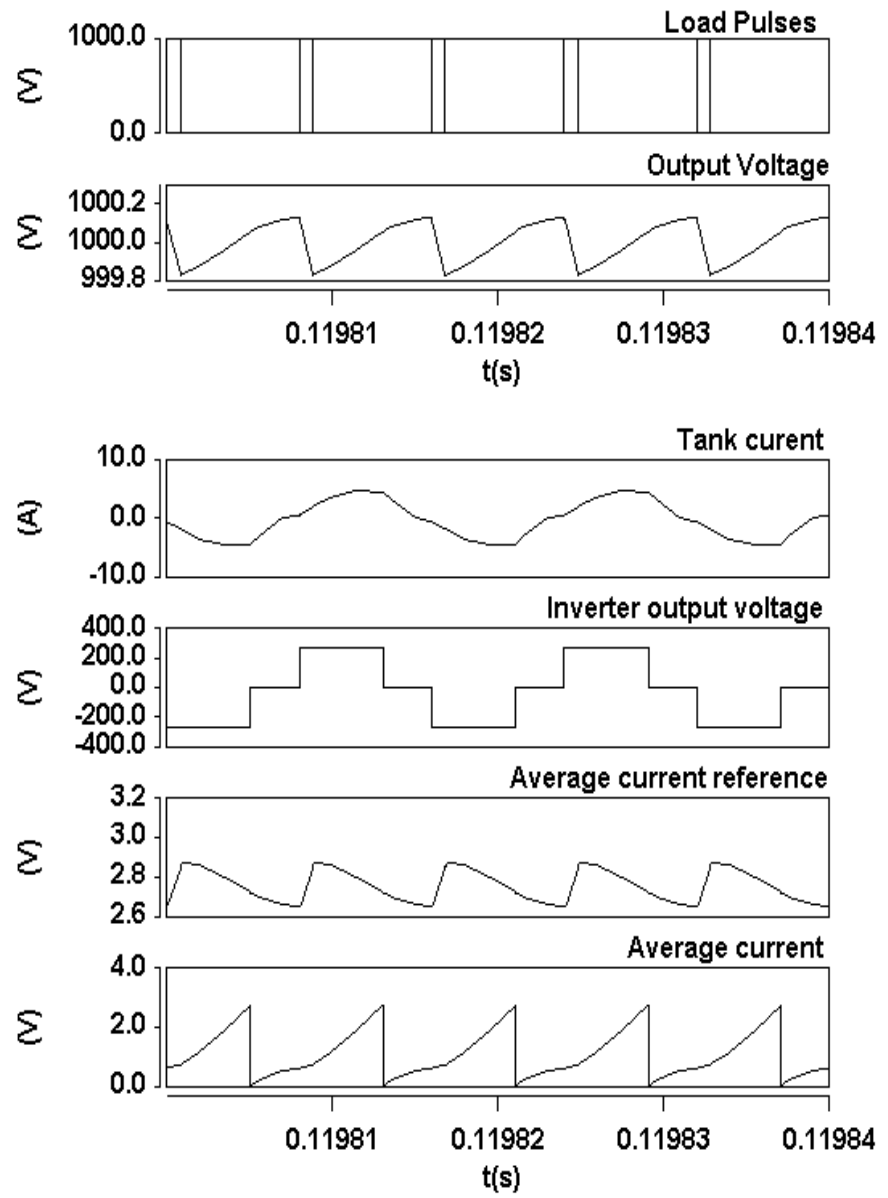

Figure 10 (c)

\section{REFERENCES}

[1] A.S. Rostad, C.T.Mc Cown, and D.O. Lawrence, “ Application of the Venable converter to a series of Satellite TWT power processors," in IEEE - PESC , 1976, pp. $104-111$.

[2] B.P.Israelsen, J.R. Martin, C.R. Reeve and V.S. Scown, “ A $2.5 \mathrm{KV}$ high - reliability TWT power supply: Design techniques for high efficiency and low ripple," in IEEE PESC, 1977, pp.212 - 222.

[3] S.D. Johnson, A.F. Witulski, and R.W. Erickson, “ Comparison of resonant topologies in high voltage DC applications," in IEEE Trans. on Aero. And Elect. Systems, vol.24, No.3, May 1988, pp.263-274.

[4] Y. Cheron, H.Foch, and J. Salesses, "Study of a resonant converter using power transistor in a $25 \mathrm{KW} \mathrm{X}$ - ray tube power supply," in IEEE - PESC , 1985, pp. 295 - 306.

[5] V. Garcia, M. Rico, M.M. Hernando, and J. Uceda, " An optimized DC to DC converter topology for high voltage pulse load applications," in IEEE - PESC, 1994, pp. 1413 $-1421$.

[6] I.J. Pitel, " Phase - modulated resonant power conversion techniques for high frequency inverters," in IEEE Trans. on Ind. Appl., 1986, vol.22, pp. $1044-1051$.
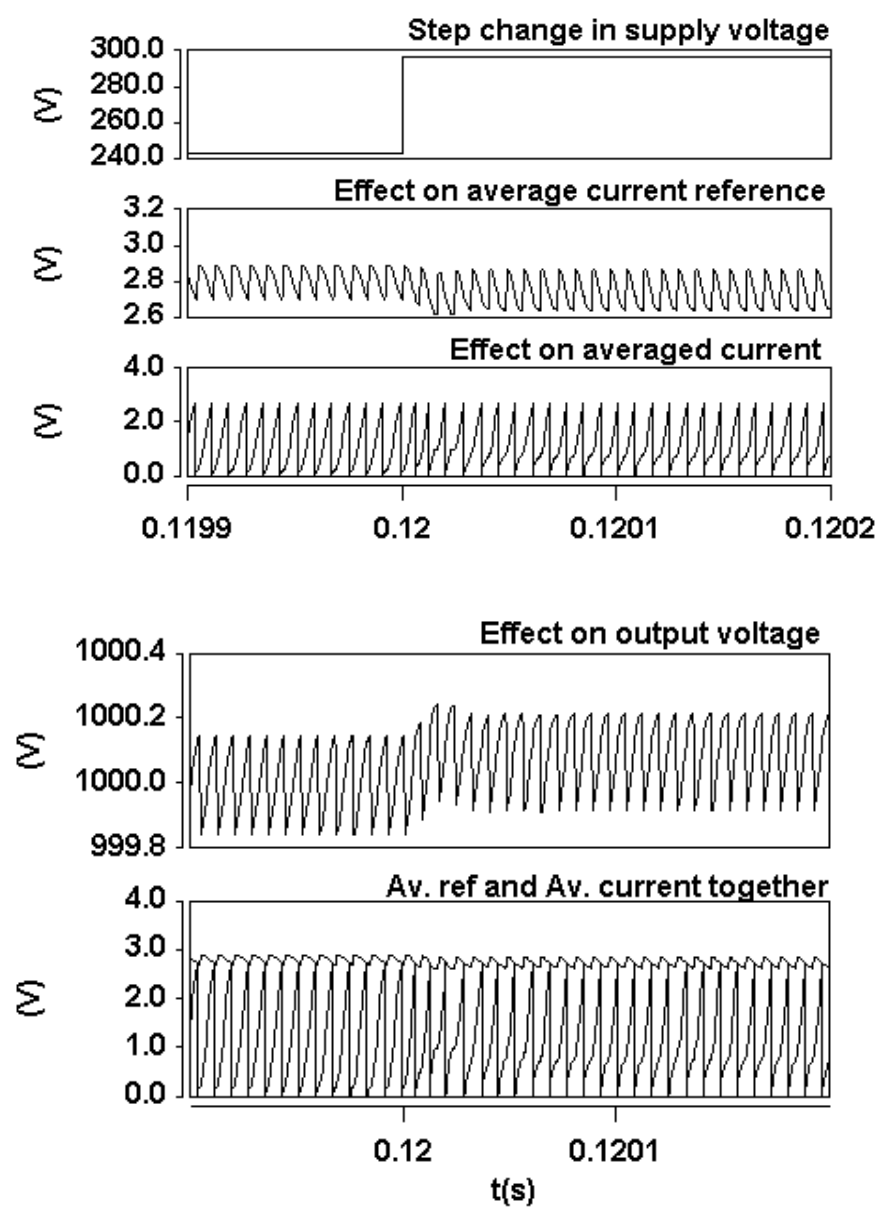

Figure $10(d)$

[7] F.S. Tsai, and F.C. Lee, “ constant frequency, phase modulated resonant power processors," in proc. IEEE, IAS Annual meeting, 1986, pp. $617-622$.

[8] K.D.T. Ngo, “ Analysis of a series resonant converter pulse - width - modulated or current - controlled for low switching loss," in IEEE Trans. on Power Electronics, vol.3, No.1, Jan., 1988, pp. $55-63$. 